\title{
Chickpea processing does not impact postprandial glycaemic response
}

\author{
M.S. Hafiz ${ }^{1,2}$, M.D. Campbell ${ }^{1}$, C. Orfila ${ }^{1}$ and C. Boesch ${ }^{1}$ \\ ${ }^{1}$ School of Food Science and Nutrition, University of Leeds, Leeds, United Kingdom and \\ ${ }^{2}$ Faculty of Applied Medical Sciences, Department of Clinical Nutrition, King Abdul-Aziz University, Jeddah, Saudi \\ Arabia
}

Chickpeas are low glycaemic index foods with delayed digestion and reduced postprandial glycaemic responses (PPGR) ${ }^{(1)}$. However, in vitro studies suggest that mechanical processing of chickpeas, that result in cell wall disruption, significantly increase both the rate and extent of starch digestion ${ }^{(2)}$. There is little evidence on the impact of processing on the acute glycaemic response elicited after chickpea intake in vivo ${ }^{(3)}$. Therefore, the aim of this study was to determine the effect of mechanical processing on PPGR in humans.

Thirteen healthy adults (4 males and 9 females) with mean ( \pm SD) age $28.7 \pm 6.6$ years and, BMI $23.2 \pm 2.5 \mathrm{~kg} / \mathrm{m}^{2}$, attended $4 \mathrm{sep}$ arate laboratory visits following an overnight fast. Participants were randomly allocated to consume a meal made of three different physical forms of chickpeas: whole chickpeas (CW), pureed chickpeas $(\mathrm{CP})$, and pasta made of chickpea flour $(\mathrm{CF})$; and control instant mashed potatoes (CT). All meals were matched for carbohydrate $(50 \mathrm{~g})$ and fat $(8 \mathrm{~g})$ content. Baseline and postprandial interstitial glucose responses were captured by continuous glucose monitoring (FreeStyle Libre pro) for a total of 24 hours. Here we report the acute postprandial responses during a 180 min observation window. Incremental area under the curve (iAUC) was calculated by the trapezoidal method, and data analysed using repeated measures ANOVA with post hoc tests using Bonferroni correction. Data are presented as mean $( \pm \mathrm{SD})$ and statistical significance was set at $p<0.05$.

All participants had significantly lower PPGR in response to each chickpea meal as demonstrated by iAUC values (180 min period) which were significantly higher for CT visit (146.7 $\pm 63.5 \mathrm{mmol} . \mathrm{min} / \mathrm{L})$ compared to CW $(62.2 \pm 67.9 \mathrm{mmol} . \mathrm{min} / \mathrm{L}), \mathrm{CF}(59.6 \pm 45.2$ mmol.min/L), and CP $(45.7 \pm 45.4 \mathrm{mmol} . \mathrm{min} / \mathrm{L})$ with $(p<0.001)$ identified by ANOVA. Similarly, incremental peak postprandial glucose (after $45 \mathrm{~min})$ was highest in CT $(2.0 \pm 1.3 \mathrm{mmol} / \mathrm{L})$ in comparison to $\mathrm{CF}(0.8 \pm 1.0 \mathrm{mmol} / \mathrm{L}), \mathrm{CW}(0.6 \pm 1.1 \mathrm{mmol} / \mathrm{L})$, and $\mathrm{CP}$ $(0.5 \pm 0.4 \mathrm{mmol} / \mathrm{L})$ with $(p=0.008)$. Due to high individual variations following chickpea product consumption, no differences between different processing methods could be established.

These results suggest that the postprandial glycaemic response to chickpeas is not impacted by mechanical processing. This may relate to higher protein content and presence of dietary fibre.

1. Augustin LSA, Chiavaroli L, Campbell J et al. (2016) Nutr J 15.

2. Dhital S, Bhattarai R, Gorham J et al. (2016) Food \& Function 7, 1367-1379.

3. Anderson G, Liu Y, Liu Y et al. (2014) Br J Nutr 112, 1966-1973. 